\title{
PEQUENAS CENTRAIS HIDRELÉTRICAS: cenários e perspectivas no estado do Paraná
}

\author{
SMALL HYDRO: scenarios and prospects in the state of Paraná \\ Bruna Caroline Kotz Kliemann, Rosilene Luciana Delariva \\ Universidade Estadual do Oeste do Paraná, PR, Brasil.
}

\begin{abstract}
Resumo
O Brasil e o Paraná apresentam alto potencial de geração de energia elétrica, devido as suas características geomorfológicas com altos desníveis, o que contribui para instalações de empreendimentos hidrelétricos. Neste contexto, o presente estudo teve como objetivo diagnosticar o número de PCHs construídas e as futuras instalações previstas para o estado do Paraná, bem como a distribuição espacial, potência gerada e áreas a serem alagadas. O Brasil é detentor de 460 PCHs em operação e 1696 em processo de licenciamento, incluindo o estado do Paraná que possui 32 PCHs e 224 PCHs em processo de licenciamento. A bacia hidrográfica do rio Iguaçu e do Ivaí foram as que apresentaram o maior número de PCHs construídas, bem como, possuem a maior quantidade de potência gerada. Com relação às instalações futuras, o maior número de PCHs está projetada para a bacia hidrográfica do rio Iguaçu, seguida pela bacia do rio Piquiri. Apesar da bacia hidrográfica do Iguaçu e do Ivaí, possuírem a mesma quantidade de PCHs construídas, a bacia do Iguaçu possui maior área do reservatório e maior potencia gerada. Diante do exposto, a visualização desse cenário busca atentar autoridades, cientistas, bem como defensores ambientais sobre os riscos e impactos previstos.
\end{abstract}

Palavras-chave: Barramentos, Bacias Hidrográficas, Paraná, Impactos ambientais.

\begin{abstract}
Brazil and Paraná have a high potential for electric energy generation, due to its geomorphological characteristics with high unevenness, which contributes to the hydroelectric projects facilities. In this context, this study aimed to diagnose the number of SHPS built and future facilities expected for the state of Parana, and also the spatial distribution, power generated and areas to be flooded. Brazil is holder of 460 SHPs in operation and 1696 in the licensing process, including the state of Paraná, which has 32 SHPs and 224 SHPs in licensing process. The hydrographic basin of the Iguaçu River and the Ivai were the ones that had the largest number of built SHPs, as well, they have the greatest amount of generated power. With regard to the future facilities, the largest number of SHPs is projected to the hydrographic basin of Iguaçu River, followed by the Piquiri River basin. Although the hydrographic basin of Iguaçu and Ivai have the same amount of built SHPs, the basin of Iguaçu has a larger area of the reservoir and higher generated power. Given the above, the view for this scenario seeks to heed the authorities, scientists and environmental advocates about the risks and expected results.
\end{abstract}

Keywords: Buses, Hydrographic Basins, Paraná, Environmental Impacts. 


\section{Introdução}

As pequenas centrais hidrelétricas foram os primeiros empreendimentos hidroelétricos construídos no Brasil no final do século XIX. Foram conceituados oficialmente no ano de 1988, na portaria $\mathrm{n}^{\mathrm{o}}$ 109, do Departamento Nacional de Águas e Energia Elétrica - DNAEE. Este documento considerava como Pequenas Centrais Hidrelétricas (PCHs), os empreendimentos que operassem a fio d'água, barragens e vertedouros com altura máxima de 10 metros, potência total instalada de até 10,0 MW, entre outros (FARIAS, 2014). Entretanto, o conceito de $\mathrm{PCH}$ passou por diversas modificações e a principal regulamentação que vigora no momento é a Resolução no 394, de 04 de dezembro de 1998 que normatiza que o empreendimento que possuir potencial hidráulico superior a $1.000 \mathrm{~kW}$ e igual ou inferior a $30.000 \mathrm{~kW}$ e a área do reservatório igual ou inferior a 3,0 $\mathrm{km}^{2}$, é considerado uma pequena central hidrelétrica (BRASIL, 1998).

Em 2003, foi editada uma nova resolução para o enquadramento também em $\mathrm{PCHs}$, de empreendimentos que possuam área do reservatório superior a $3 \mathrm{~km}^{2}$. Para isso, é necessário que esses empreendimentos se enquadrem em dois critérios: atendimento à inequação (1):

$$
A \leq \frac{14,3 \times P}{H_{b}}(1)
$$

Sendo $\mathrm{P}=$ potência elétrica instalada em $(\mathrm{MW}) ; \mathrm{A}=$ área do reservatório em $\left(\mathrm{km}^{2}\right) ; \mathrm{e}$ $\mathrm{Hb}$ = queda bruta em (m), definida pela diferença entre os níveis d'água máximos normal de montante e normal de jusante. Adicionalmente, é necessário comprovar que o objetivo do dimensionamento do reservatório não é para geração de energia elétrica (BRASIL, 2003).
Dessa forma, o investimento em Pequenas Centrais Hidrelétricas se justifica pelo fato deste apresentar baixo investimento inicial, impacto ambiental reduzido, menor tempo para obtenção das licenças e construção e eficiência e rapidez na produção de energia elétrica, por ser uma produção descentralizada e com poucas perdas nos sistemas de transmissão (CANDIANI et al., 2013; FARIAS, 2014; NOWAKOWSKI et al., 2013).

Historicamente, a partir do término da segunda guerra Mundial, o Brasil teve expressivo crescimento demográfico, aceleração da urbanização e dos processos de industrialização e construção de infraestrutura de transporte rodoviário. Esse cenário resultou em maior demanda de energia primária. Dessa forma, fez-se necessária a substituição de fontes de energia menos alternativas, como por exemplo, a lenha, por outras mais eficientes como petróleo e água (TOLMASQUIM et al., 2007). Até então, embora já existissem alguns empreendimentos elétricos, o recurso energético mais utilizado era a energia térmica para abastecimento das cidades. Mesmo no ano de 1970, a principal matriz energética era a lenha, representando $48 \%$ das necessidades brasileiras no uso final de energia. $\mathrm{O}$ petróleo, no mesmo ano, já representava 36\% da demanda. Entre 1970 e 1990, o consumo de lenha reduziu para uma taxa de 2,9\% ao ano. Com a crise energética dos anos 70, o Brasil investiu nas fontes energéticas hidráulicas e de cana-de-açúcar, que tiveram um ritmo de crescimento de 6,6\% ao ano, entre os anos de 1970 e 2005 (BRONZATTI; NETO, 2008).

A instalação do primeiro aproveitamento hidrelétrico no Brasil ocorreu em 1883, na mineração Santa Maria em Diamantina e em 1889, foi instalada a Usina Bernardo Mascarenhas, a fim de atender a sua 
indústria têxtil e a iluminar a cidade de Juiz de Fora. Por isso, é considerada a primeira empresa de energia elétrica para o serviço público. Além de ser a primeira hidrelétrica de grande porte com $250 \mathrm{~kW}$ de potência gerada. Entre o período de 1920 e 1940, ocorreu um rápido crescimento na construção de Pequenas Centrais Hidrelétricas (PCHs). De 1920 para 1930 ocorreu à construção de 703 PCHs e estas foram construídas por pequenos empresários ou pelas prefeituras municipais (TIAGO FILHO; GALHARDO; FERRARI, 2006).

Na década de 1980, o Governo Federal procurou incentivar a implantação de pequenas centrais, através do Programa Nacional de Pequenas Centrais Hidrelétricas (PNPCH) do Ministério de Minas e Energia - MME, promovendo estudos, cursos, subsídios técnicos para o desenvolvimento e discussão do tema. Entretanto, apesar do programa de incentivo, este não se efetivou, e apenas no início do ano 2000, devido a uma crise energética, ocorreram progressos em relação a investimentos no setor elétrico. Assim, foram realizados mecanismos de incentivo a construção de PCHs, uma vez que estas causariam, além de outros motivos, menos impactos ambientais e uma geração de energia mais descentralizada do que uma hidrelétrica de grande porte (ALBUQUERQUE; MORAES, 2013; LEÃO; BRASIL JUNIOR, 2008; TIAGO FILHO; GALHARDO; FERRARI, 2006).

Alcoforado (1990) enfatiza que o incentivo para a implantação de pequenas centrais hidrelétricas pelas concessionárias estaduais e por empresas privadas ocorre devido a problemas financeiros da Eletrobrás e concessionárias de energia elétrica do país.

No Brasil, 95\% da energia produzida é gerada a partir de hidrelétricas. Esse cenário pode ser explicado devido às características geomorfológicas que contribuem para construção de empreendimentos hidrelétricos, representadas pela presença de rios de planalto, altos declives, vales encaixados, bem como, o grande potencial hídrico do Brasil (LOPES, 2011; RESZKA, 2013).

O estado do Paraná é considerado o terceiro estado brasileiro com maior potencial de geração de energia elétrica. Este possui 16 bacias hidrográficas, totalizando uma área de 199.852,20 km². Apresenta características geomorfológicas com altos desníveis o que contribui para instalações de empreendimentos hidrelétricos. O primeiro empreendimento do tipo Pequena Central Hidrelétrica entrou em operação em 1930 com a construção da Usina Chaminé, esta localizada na margem esquerda do rio São João, no município de São José dos Pinhais (COPEL, 1999a; PAROLIN,VOLKMER-RIBEIRO, LEANDRINI, 2010; SEMA, 2010).

Esses empreendimentos então tem um alto incentivo para sua construção, pois aparentemente provocam menos impactos ambientais, são de menor custo para construção e além disso, para sua aprovação é necessário a elaboração de um relatório de impacto ambiental simplificado, o qual analisa os impactos de forma superficial. Tais fatores indicam maior facilidade para instalação de PCHs, consequentemente uma alta quantidade de PCHs construídas e em operação, afetando assim de forma direta os rios do estado do Paraná e indiretamente a qualidade de vida da população paranaense.

Dessa forma, o presente estudo teve como objetivo diagnosticar o número de pequenas centrais hidrelétricas ( $\mathrm{PCHs}$ ) construídas e as futuras instalações previstas para o estado do Paraná, bem como a distribuição espacial, potência gerada e áreas a serem alagadas. A visualização desse cenário busca atentar autoridades, cientistas, bem como 
defensores ambientais sobre os riscos e impactos previstos.

\section{Metodologia}

A metodologia empregada nessa pesquisa foi um estudo descritivo e exploratório, com análise dos dados através de uma abordagem qualitativa-quantitativa. Inicialmente realizou-se um levantamento das produções científicas sobre a matriz energética brasileira e os possíveis impactos ambientais causados por esses empreendimentos.

As informações sobre a quantidade de pequenas centrais hidrelétricas instaladas ao longo dos rios do estado do Paraná, os rios, bacias, regiões, capacidade de geração de energia, bem como área do reservatório, foram obtidos a partir da base de dados disponibilizados nos sites oficiais, incluindo ANEEL (Agência Nacional de Energia Elétrica), SIGEL (Sistema de informação da ANEEL), ANA (Agência Nacional de Águas), órgãos ambientais, bem como produções científicas a cerca desse assunto.

Para demonstração dos dados quanto ao destino de energia, foi utilizado a classificação da ANEEL (2014a), onde SP (serviço público) refere-se a empresas ou pessoa jurídica que presta serviços públicos de energia elétrica; APE (autoprodutor de energia), são empresas ou pessoa jurídica que possuem autorização para produzir energia elétrica destinada apenas ao seu uso e PIE (produtor independente de energia), produzem energia elétrica para uso comercial de toda ou parte da energia produzida por sua conta e risco.

Nesse estudo, para fins de verificação das tendências e área de reservatório e potencia geradas, foram excluídos três empreendimentos (Santa Clara I, Mourão I e São Jorge), que apresentam uma área do reservatório que perpassa $3 \mathrm{~km}^{2}$, embora conste na resolução $\mathrm{N}^{\circ}$ 652, de 9 de dezembro de 2003, que se o empreendimento atender a inequação (1)

$$
A \leq \frac{14,3 \times P}{H_{b}}(1)
$$

Além disso, se o objetivo do dimensionamento do reservatório não for para geração de energia elétrica, como citados anteriormente, poderá ser considerada como uma Pequena Central Hidrelétrica (BRASIL, 2003). Ademais, a inserção dessas PCHs, causam distorções nos dados que especificamente temos como objetivos.

As relações entre números de pequenas centrais hidrelétricas construídas e futuras instalações no Paraná e no Brasil e por bacias hidrográficas foram obtidos calculando as frequências absolutas e relativas percentuais. A relação entre potência gerada e área do reservatório foi calculada através da análise de regressão linear e representação da função da reta de regressão por meio do método dos mínimos quadrados. Ambas as relações foram calculados no programa Excel. A representação gráfica foi realizada a partir do programa Statistica 7. O mapa com a distribuição de PCHs construídas e em fase de licenciamento no Estado do Paraná foi construído utilizando o programa Qgis 2.4.0.

\section{Resultados}

O estado do Paraná possui atualmente, no total 32 pequenas centrais hidrelétricas (PCHs) distribuídas em suas bacias hidrográficas, totalizando $258.152 \mathrm{~kW}$ de potência gerada (ANEEL, 2013). Estes empreendimentos estão distribuídos por toda a extensão do Paraná, localizados especificamente nas bacias do Paraná III, Tibagi, Iguaçu, Ribeira, Litorânea, Itararé e Ivaí.

Destas 32, três não foram consideradas para os demais dados, visto que a $\mathrm{PCH}$ de Santa Clara I, que possui uma grande área do reservatório de $20,5 \mathrm{~km}^{2}$, porque está 
acoplada a usina hidrelétrica Santa Clara, utilizando o seu reservatório (LOTURCO, 2004). Mourão I também tem um grande reservatório $\left(11,3 \mathrm{~km}^{2}\right)$, pois está acoplada a usina hidrelétrica Mourão I (COPEL, 1999b). Já a PCH São Jorge é resultado da ampliação do complexo da barragem de sumidouro, que foi a usina mais antiga do Paraná até ser desativada. Este complexo de barragem possui uma área de reservatório de $7,2 \mathrm{~km}^{2}$, a mesma área da PCH São Jorge (COPEL, 1999c).

Estão previstos 224 empreendimentos hidrelétricos de pequeno porte para os próximos anos. Estes estão em diferentes estágios do processo de obtenção de licenciamento mediante aos órgãos ambientais e a ANEEL (Figura 1).

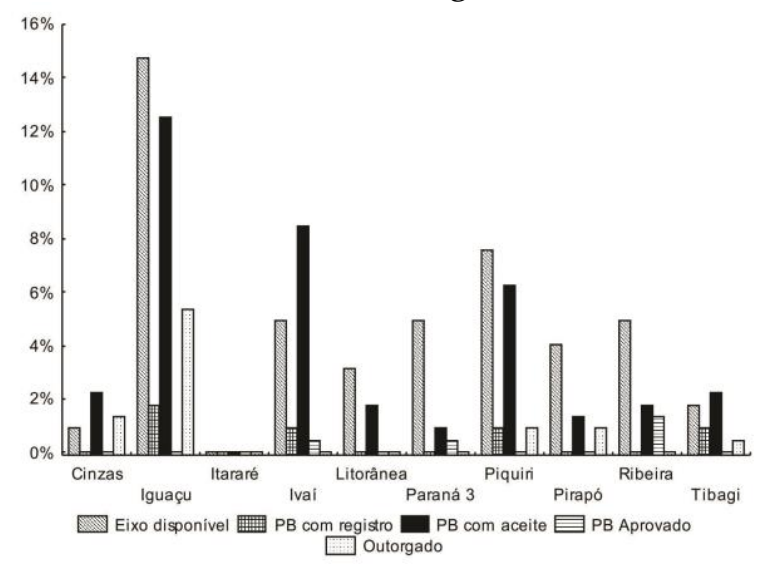

Figura 1. Porcentagem de PCHs por bacia hidrográfica a partir do estágio de licenciamento na qual se encontra o empreendimento.

Dentre os 224 empreendimentos, sete foram concedidas no ano de 2014 pela licença de instalação prévia. Sendo assim, o atual cenário energético paranaense de pequenas centrais hidrelétricas é composto por 32 PCHs construídas e 224 futuras instalações (Figura 2). A mesma tendência é visualizada quando se considera o panorama brasileiro, que também tende a crescer nos próximos anos, no qual existem 460 PCHs em operação e 1696 em processo de licenciamento (Figura 2).

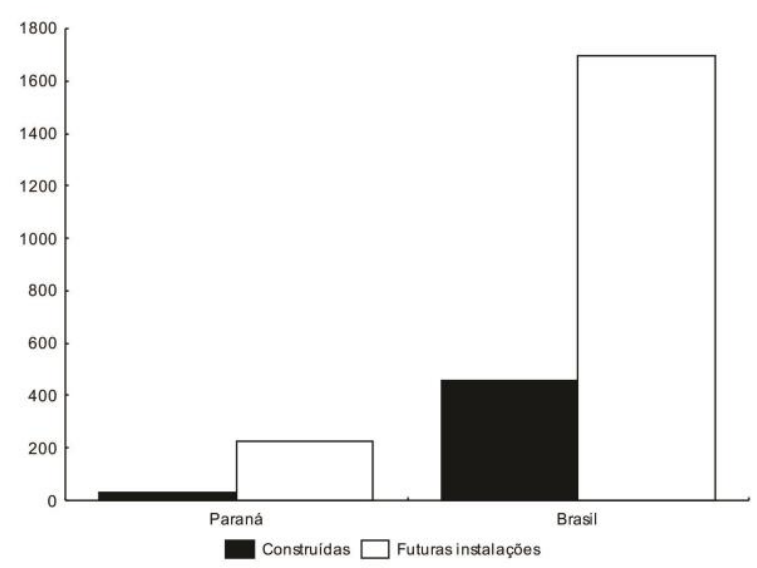

Figura 2. Número absoluto de PCHs construídas e inventariadas no estado do Paraná e no Brasil.

Analisando o cenário de PCHs por bacia hidrográfica, verifica-se que a bacia hidrográfica do rio Iguaçu $(28,13 \%)$ e a bacia do rio Ivaí $(28,13 \%)$ foram as que apresentaram o maior número de pequenas centrais hidrelétricas construídas (Figura 3). Estas bacias também apresentam a maior quantidade de potência gerada (Figura 4).

Com relação às instalações futuras, o maior número de $\mathrm{PCH}$ está projetado para a bacia hidrográfica do rio Iguaçu $(34,67 \%)$, seguida pela bacia do rio Piquiri $(15,56 \%)$ (Figura 3).

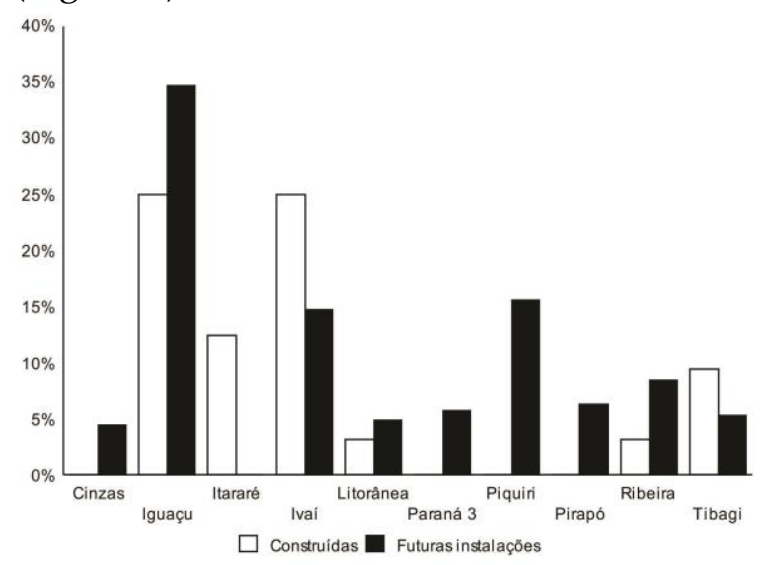

Figura 3. Percentagem de PCHs construídas e inventariadas nas bacias hidrográficas do estado do Paraná. 
A bacia hidrográfica do rio Iguaçu foi a que apresentou a maior área represada dentre as bacias hidrográficas ocupadas atualmente por pequenas centrais hidrelétricas no estado do Paraná (Figura 4), ou seja, apesar da bacia hidrográfica do Iguaçu e do Ivaí, possuírem a mesma quantidade de PCHs construídas, a bacia do Iguaçu possui maior área do reservatório e maior potencia gerada.

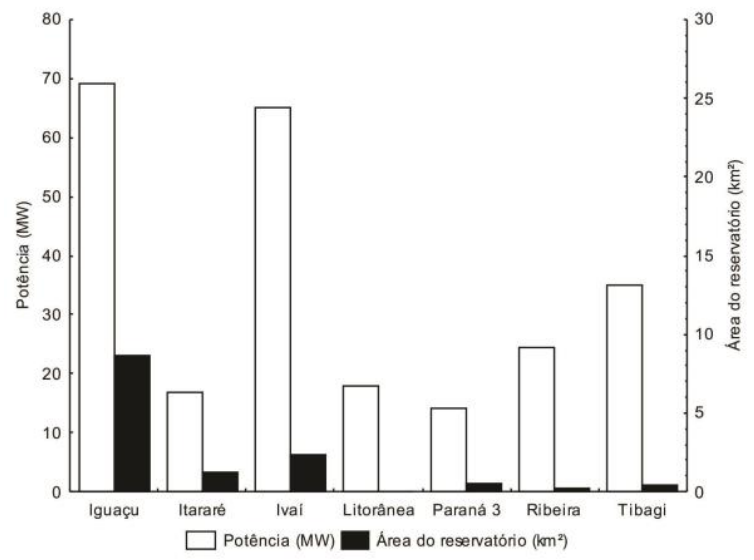

Figura 4. Relação potência gerada versus área do reservatório referente às $\mathrm{PCH}$, por bacia hidrográfica no estado do Paraná.

Entretanto, verifica-se que a área do reservatório não está diretamente ligada com a capacidade de geração de energia elétrica da PCH. Observando as linhas de tendência da figura 5, os quais demonstram a partir do valor de $\mathrm{R}^{2}$, baixa relação entre a potência gerada e a área do reservatório, com exceção da bacia do Ivaí, onde a linha de tendência se eleva com o aumento da área do reservatório, ou seja, o aumento da área do reservatório eleva a potência gerada (Figura 5), apesar de possuir $\mathrm{PCHs}$ com pequenos reservatórios $\left(0,001\right.$ a $\left.0,620 \mathrm{~km}^{2}\right)$ (Figura7).
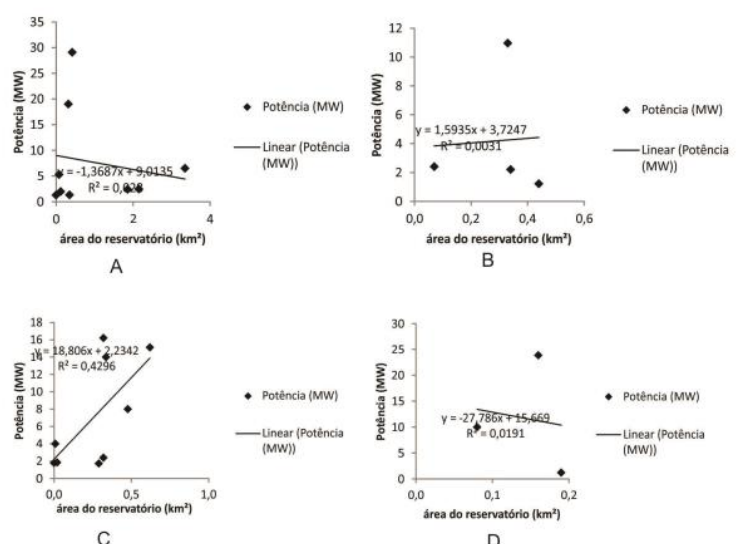

Figura 5. Relação potência gerada versus área do reservatório das $\mathrm{PCHs}$ em bacias hidrográficas com maior número desses empreendimentos. A. Bacia do Iguaçu; B Bacia do Itararé; C. Bacia do Ivaí; D. Bacia Tibagi.

Outro fator de grande relevância é o destino da energia produzida, que pode ser serviço público (SP), autoprodução de energia (APE) e produção independente de energia (PIE). Verifica-se que a produção independente de energia é o destino de energia da maioria das $\mathrm{PCH}$ construídas (Figura 6), ou seja, estas foram construídas a fim de produzir energia para fins comerciais.

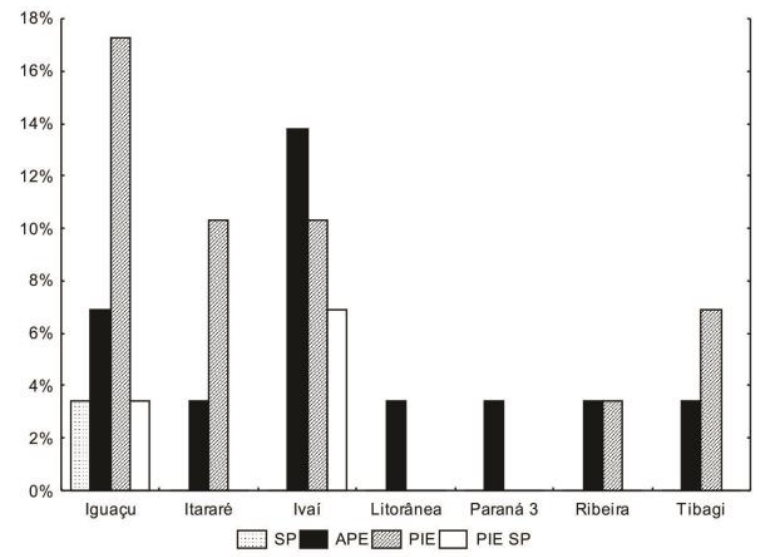

Figura 6. Distribuição de PCHS de acordo com o destino da energia gerada por bacia hidrográfica do estado do Paraná. $\mathrm{SP}=$ Serviço Público; APE= Auto produção de energia; PIE= Produção independente de energia. 
A partir da figura 7, pode-se verificar e confirmar os resultados acima, pois este apresenta a localização dos empreendimentos atuais e futuros e as respectivas áreas do reservatório. As $\mathrm{PCH}$ estão mais concentradas nas bacias hidrográficas do Iguaçu e do Ivaí. A bacia do Iguaçu apresentado PCHs com áreas de reservatórios maiores e a do Ivaí áreas dos reservatórios menores. Verifica-se que apesar de ambas apresentarem a mesma quantidade de $\mathrm{PCHs}$, a área do reservatório é diferente, bem como a potência gerada.

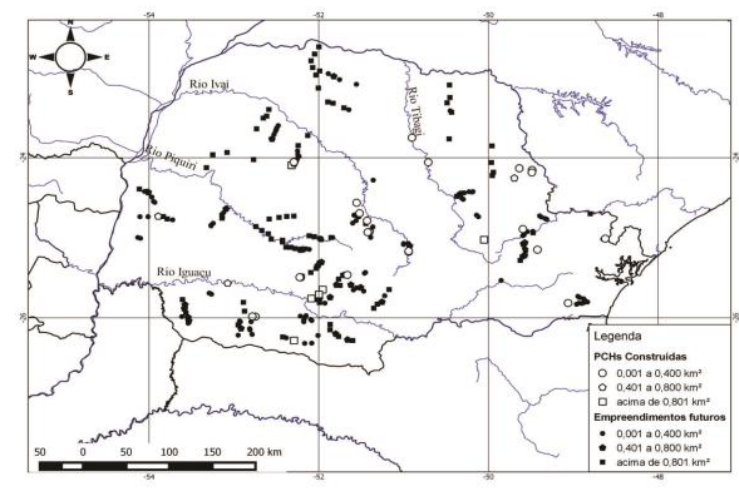

Elaboração do autor.

Figura 7. Distribuição de PCHs construídas e em fase de licenciamento no Estado do Paraná (dados obtidos da ANEEL, 2014b).

\section{Discussão}

O cenário visualizado nesse levantamento demonstra que as bacias hidrográficas dos rios Iguaçu e Ivaí foram as que apresentaram o maior número de Pequenas Centrais Hidrelétricas construídas e em processo de licenciamento. As características geomorfológicas peculiares de cada bacia explicam esses resultados. A bacia hidrográfica do Iguaçu congrega áreas representadas nos três planaltos paranaenses, apresentando uma variação de altitude de 830 metros. Além disso, possui uma alta disponibilidade hídrica (291 mil L/s), que corresponde $25 \%$ do volume hídrico total do estado. Por outro lado, a bacia hidrográfica do Ivaí apresenta em seus $798 \mathrm{~km}$ de extensão inúmeros saltos, corredeiras e cachoeiras, com altitude que pode chegar a 1.300 metros, demonstrando que seu relevo apresenta elevados desníveis, variando de $10 \mathrm{~m} / \mathrm{km}$ até a declividade mínima entre 0 e $2 \mathrm{~m}$. O rio Ivaí possui disponibilidade hídrica que representa $20 \%$ do total do estado, com $233 \mathrm{mil} \mathrm{L/s} \mathrm{(PAROLIN,}$ VOLKMER-RIBEIRO, LEANDRINI, 2010; BAUMGARTNER et al., 2012; JÚLIO JR, BONECKER; AGOSTINHO, 1997; SEMA, 2010).

A menor declividade da bacia do Ivaí em relação à bacia do Iguaçu pode explicar a relação direta entre a área do reservatório com a potência gerada das $\mathrm{PCH}$ da bacia do Ivaí, ou seja, as PCHs precisam de uma área do reservatório maior para gerar potências mais elevadas, já que possuem declividades menores.

$\mathrm{O}$ atual cenário de energia elétrica do Paraná, que tem como principal agente os produtores independentes de energia, os quais comercializam a energia produzida, é resultado do investimento em empreendimentos de pequeno porte, assim como, a crise energética que ocorreu em 2000, a qual provocou um maior incentivo à construção de PCHs por empresas públicas e privadas (ALBUQUERQUE; MORAES, 2013; LEÃO; BRASIL JUNIOR, 2008; NOWAKOWSKI et al., 2013; TIAGO FILHO; GALHARDO; FERRARI, 2006).

$O$ grande incentivo à implantação de empreendimentos hidrelétricos, bem como a grande demanda pela eletricidade ocasionada pelo aumento da população, como mencionado anteriormente, é consequência, do fato de o Brasil ocupar o primeiro lugar do mundo no ranking de recurso hídrico. Entretanto, a construção de empreendimentos de grande porte como a Usina de Belo Monte que está sendo construído no rio Xingu, no estado do Pará, provocam elevados impactos socioambientais. Desta forma, é preferível o 
investimento em empreendimentos de pequeno porte como as Pequenas Centrais Hidrelétricas (NOWAKOWSKI et al., 2013).

Os estudos com relação aos impactos ambientais de PCHs ainda são incipientes. Entretanto, os levantamentos preliminares, especialmente dos Estudos de impacto ambientais (EIA) elaborados pelas empresas licitadoras, descrevem que os impactos provocados afetam negativamente as rotas migratórias dos peixes; o fluxo de água que diminui a jusante; a perda de habitats, pois um ambiente que antes era lótico passa a ser lêntico, alterando também as comunidades de peixes, a introdução de espécies exóticas como uma forma de repovoamento, além da eutrofização do reservatório devido à vegetação que fica submersa durante o enchimento do reservatório (SILVE; POMPEU, 2011).

Outra problemática refere-se ao fato de que o número de empresas que realizam pesquisas sobre a fauna de peixes dos rios que serão represados e quais as medidas mitigadoras para tais impactos é baixa, ou seja, poucas empresas realizam uma pesquisa minuciosa a cerca das espécies de peixes que serão afetadas, pois para a aprovação de um projeto de construção e operação de uma PCH, a empresa licitadora não necessita fazer um estudo mais aprofundado dos impactos ambientais, como um Estudo de Impacto Ambiental Relatório de Impacto Ambiental (EIARIMA). É necessário apresentar apenas um Relatório Ambiental Preliminar (RAP), que, analisa os impactos ambientais de forma superficial e pontual, não considerando as outras PCHs instaladas na mesma bacia hidrográfica (ALBUQUERQUE, 2012; CANDIANI et al., 2013; MACMANAMAY et al., 2014; SILVE; POMPEU, 2011).

Segundo Bakken et al (2014), apesar das pequenas centrais hidrelétricas serem consideradas de menor impacto, quando em cascata elas alteram a conectividade no decorrer da bacia hidrográfica provocando fragmentos, os quais atingem principalmente os animais silvestres.

Anderson, Freeman, Pringle (2006), salientam que o principal impacto ambiental associado a hidrelétricas independente de sua dimensão é a alteração na velocidade da água, afetando assim o transporte de sedimento e a temperatura da água, bem como, a quantidade e qualidade dos habitats aquáticos. Apontam ainda, a fragmentação das comunidades de peixes devido à presença da barragem, o qual impede o fluxo normal dos peixes a montante e a jusante desta barreira física. Os peixes conseguem atravessar a barragem apenas em períodos de altas vazões de água, entretanto não conseguem retornar. Como consequência, ocorre o isolamento de populações a montante de barragem, provocando diminuição na diversidade e até a eliminação total de espécies altamente móveis. Ademais, a compensação de fluxo à jusante da barragem fornece água suficiente para os peixes oportunistas, mas pode não ser suficiente para espécies com exigências reprodutivas mais desenvolvidas (VOWLES et al., 2014; MACMANAMAY et al., 2014).

Outro impacto a ser considerado sobre a fauna de peixes é a mortalidade ou lesões provocadas pelas lâminas das turbinas quando o peixe atravessa essas estruturas. Em pequenas centrais hidrelétricas, os danos letais ocorrem com menos frequência. Porém, a passagem pelas turbinas provoca comprometimento nas aptidões individuais, pois alteram o comportamento, provocam stress fisiológico, tornando os peixes mais susceptíveis a predação (VOWLES et al., 2014).

Cabe ainda destacar que dentre os impactos das PCHs, tem-se as alterações na geografia local, pois a barragem e a usina tomarão o lugar das matas, das habitações e das plantações, interferindo diretamente na vida das pessoas que ali habitam, e também 
da fauna e flora ali presente (RESZKA, 2013).

\section{Conclusão}

Os dados aqui levantados demonstram que os rios paranaenses estão sendo e serão acentuadamente alterados pelos empreendimentos hidrelétricos. Esse cenário é preocupante, especialmente tendo em vista os impactos ambientais provocados pela construção das barragens, formação de reservatórios, casas de força e canais - condutos metálicos. Essa grande quantidade de barramentos se dá principalmente em virtude das PCHs disporem de uma série de vantagens para serem implantadas, incluindo desde programas governamentais de financiamento até mudanças na legislação, tanto do setor elétrico quanto do ambiental, permitindo que se faça um comparativo dos desdobramentos das eletroestratégias no caso das PCHs. Além disso, até mesmo o conceito de Pequena Central Hidrelétrica tem passado por mudanças, o que permite que um maior número de empreendimentos hidrelétricos se enquadre nos critérios, bem como usufruam dos benefícios legais que este tipo de empreendimento oferece.

\section{Referências}

\section{ALBUQUERQUE, R de. M. As Pequenas}

Centrais Hidrelétricas do rio Iratim e seus impactos socioambientais. In: XIII Jornada de Trabalho, 1., 2012, Presidente Prudente. Anais eletrônicos... Presidente Prudente: CEGet, 2012. p. 1-21.

Disponível em:

http://www.proceedings.scielo.br /pdf/jtrab/n1/31.pdf. Acesso em: 23 de julho de 2014.

ALBUQUERQUE, R de. M.; MORAES, G. G de. ELETROESTRATÉGIAS: as pequenas centrais hidrelétricas e os meandros do setor elétrico brasileiro. Campo-

Território: revista de geografia agrária, $\mathrm{v}$. 8, n. 16, p. 379-398, ago., 2013.

ANDERSON, E.P.; FREEMAN, M.C.; PRINGLE,C.M. Ecological consequences of hydropower development in central America: impacts of small dams and water diversion on neotropical stream fish assemblages. River Res. Applic., v.22, n.4, p.397-411, 2006.

ANEEL (Agência Nacional de Energia Elétrica) (2014a). Informações técnicas. Disponível em:

http://www.aneel.gov.br/area.cfm?id_are $\mathrm{a}=41$. Acesso em: 15 set. 2013.

ANEEL (Agência Nacional de Energia Elétrica)(2013).Banco de Informações de Geração. Disponível em: $<$ http://www.aneel.pr.gov.br >. Acesso em: 29 nov. 2013.

ANEEL( Agência Nacional de Energia Elétrica)(2014b). Sistema de Informações Georreferenciadas do Setor Elétrico. Disponível em: http://sigel.aneel.gov.br/sigel.html. Acesso em: 16 ago. 2014.

BAUMGARTNER, G. et al. Peixes do baixo rio Iguaçu. Maringá: Eduem, 2012, 203 p.

BAKKEN, T.H; AASE, A.G.; HAGEN, D.; SUNDT, H.; BARTON, D.N.; LUJALA, P. Demonstrating a new framework for the comparison of environmental impacts from small- and large-scale hydropower and wind power projects. Journal of Environmental Management, v.140, p.93101, 2014.

BRASIL. Resolução da ANEEL, N 394, DE 4 DE DEZEMBRO DE 1998. Estabelece os critérios para o enquadramento de empreendimentos hidrelétricos na condição de pequenas centrais hidrelétricas. Agência Nacional de Energia Elétrica. Disponível em: http://www.aneel.gov.br/cedoc/res19983 94.pdf. Acesso em: 15 out. 2014.

BRASIL. Resolução da ANEEL, N ${ }^{\circ}$ 652, DE 9 DE DEZEMBRO DE 2003. Estabelece os 
critérios para o enquadramento de aproveitamento hidrelétrico na condição de Pequena Central Hidrelétrica $(\mathrm{PCH})$. Agência Nacional de Energia Elétrica. Disponível em:

http://www.aneel.gov.br/cedoc/res20036 52.pdf. Acesso em: 15 out. 2014.

BRONZATTI, F. L.; IAROZINSKI NETO, A. Matrizes energéticas no Brasil: cenário 2010-2030. In: ENCONTRO NACIONAL DE ENGENHARIA DE PRODUÇÃO, 28., 2008, Rio de Janeiro. Anais eletrônicos... Rio de Janeiro: Abepro, 2008. Disponível em: www.abepro. org.br/biblioteca/ enegep2008_TN_STO_077_541_11890.pd f. Acesso em: 15 set. 2014.

CANDIANI, G. et al. Estudo de Caso: Aspectos Socioambientais da Pequena Central Hidrelétrica (PCH)-Queluz-Sp, na Bacia do Rio Paraíba do Sul. Revista do Departamento de Geografia, São Paulo, v. 25, p. 98-119, 2013.

COPEL (1999a). Relatório Ambiental Usina Hidrelétrica Chaminé. Disponível em: http://www.copel.com/hpcopel/root/pag copel2.nsf/arquivos/relambientalche/\$FI LE/RelAmbientalCHE.pdf. Acesso em: 15 out. 2013.

COPEL(1999b). Relatório Ambiental Usina Hidrelétrica Mourão I. Disponível em: http://www.copel.com/hpcopel/root/pag copel2.nsf/arquivos/relambientalmou/\$FI LE/RelAmbientalMOU.pdf . Acesso em: 12 set. 2014.

COPEL(1999c). Relatório Ambiental Usina Hidrelétrica São Jorge. Disponível em: http://www.copel.com/hpcopel/root/pag copel2.nsf/arquivos/relambientalsjr/\$FIL E/RelAmbientalSJR.pdf. Acesso em: 10 ago.2014.

FARIAS, R de. A.N. Avaliação dos Procedimentos de Autorização e Outorga para Implantação de Pequenas Centrais Hidrelétricas. 2014. 259 f. Dissertação (Mestrado em Tecnologia Ambiental e Recursos Hídricos). Pós-
Graduação em Tecnologia Ambiental e Recursos Hídricos. Faculdade de Tecnologia da Universidade de Brasília. Brasília, 2014.

RESZKA, R. Usinas Hidrelétricas: alterações na Geografia local. 2013. 45 f.

Monografia (Graduação em Geografia). Universidade Regional do Noroeste do Estado do Rio Grande do Sul (UNIJUÍ), Rio Grande do Sul, 2013.

LEÃO, L. L.; BRASIL JUNIOR, A.C.P. Mecanismos de Incentivos à Construção de Pequenas Centrais Hidrelétricas. In: IV Encontro Nacional de ENANPPAS, 2008, Brasília. Anais eletrônicos... Brasília: ANPPAS, 2008, p. 1-20. Disponível em: http://www.anppas. org.br/encontro4/cd/ARQUIVOS/GT4-963-20080424154016.pdf. Acesso em: 20 abr. 2014.

LOTURCO, B. Usina Santa Clara. Téchne. ed. 93, 2004. Disponível em:

http://techne.pini. com.br/ engenhariacivil/93/artigo286327-1.aspx. Acesso em: 18 ago. 2014

LOPES, G. de C. Impactos Socioambientais na implantação da Pequena Central Hidrelétrica (PCH) São Francisco em Toledo -PR. In: I Seminário Internacional dos Espaços de Fronteiras. III Seminário Regional sobre Território, Fronteira e Cultura. VII Expedição Geográfica da Unioeste: Espaços de Fronteira Território e Ambiente. Marechal Cândido Rondon, 2011. Anais Eletrônicos... Marechal Cândido Rondon, UNIOESTE, 2011, p. 1-11. Disponível em: http://cacphp.unioeste.br/eventos/geofro nteira/anais2011/Arquivos/Artigos/GEST AO/Artigo78.pdf. Acesso em: 30 set. 2013.

MACMANAMAY, R.A.; SAMU, N.; SHIHCHIEH, K.; BEVELHIMER, M.S.; HETRICK, S.C. A Multi-scale Spatial Approach to Address Environmental Effects of Small Hydropower Development. Environmental 
Management, Nova York, 16 set. 2014.

Disponível em:

http://www.academia.edu/8395572/A_M

ultiscale_Spatial_Approach_to_Address_

Environmental_Effects_of_Small_Hydro power_Development. Acesso em: 15 out. 2014.

NOWAKOWSKI, G.A.A. et al. Pequenas

Centrais Hidrelétricas no Estado do

Paraná: Dilemas e Oportunidades. In: IV

Congresso Brasileiro de Gestão

Ambiental, Salvador, 2013. Anais

eletrônicos... Salvador, IBEAS, 2013, p. 1-

11. Disponível em: http://www.ibeas.org. br/congresso/Trabalhos2013/X-003.pdf.

Acesso em: 10 out. 2014.

PAROLIN, M.; RIBEIRO- VOLKMER, C.;

LEANDRINI, J.A. Abordagem ambiental interdisciplinar em bacias hidrográficas no Estado do Paraná. Campo Mourão:

Felcicam, 2010, p.170.

RESZKA, R. Usinas Hidrelétricas: alterações na Geografia local. 2013. 45 f.

Monografia (Graduação em Geografia).

Universidade Regional do Noroeste do

Estado do Rio Grande do Sul (UNIJUÍ),

Rio Grande do Sul, 2013.

SEMA (Secretaria de Estado do Meio

Ambiente e Recursos Hídricos). Bacias

hidrográficas do Paraná. Disponível em:

http://www.meioambiente.pr.gov.br/arq uivos/File/corh/

Revista_Bacias_Hidrograficas_do_Paran

a.pdf. Acesso em: 15 nov. 2013.

SILVE, E.M; POMPEU, P dos, S. Análise crítica dos estudos de ictiofauna para o licenciamento ambiental de $40 \mathrm{PCH}$ no estado de Minas Gerais. PCH Noticias \& SHP News. n.37,abr/mai/jun,2008, p.22-

26. Disponível em:

$<$ http://www.cerpch.unifei.

edu.br/arquivos/ revistas/37.pdf $>$. Acesso em: 17 set. 2014.

TIAGO FILHO, G. L.; GALHARDO, C. R; FERRARI, J. T. A evolução histórica do conceito das pequenas centrais hidrelétricas no Brasil. In: V Simpósio
Brasileiro Sobre Pequenas e Médias

Centrais Hidrelétricas, 2006,

Florianópolis. Anais... Florianópolis:

Universidade Federal de Itajubá, 2006, p. 2-8.

TOLMASQUIM, M. T.; GUERREIRO, A.; GORINI, R. Matriz Energética Brasileira: uma prospectiva. Novos Estudos, n.79, p.47-69, 2007.

VOWLES, A.S.; KARLSSON, S.P.;

UZUNOVA, E.P.; KEMP,P.S. The importance of behaviour in predicting the impact of a novel small-scale hydropower device on the survival of downstream moving fish. Ecological Engineering, v.69, p. 151-159, 2014. 